\title{
Kobalt Katkılı Kalsiyum Manganez Oksit Numunelerin Sentez ve Karakterizasyonu
}

\author{
Tankut Ateş $^{1 *}$, Süleyman Köytepe ${ }^{2}$, Ömer Kayg $11^{3}$
}

Geliş / Received: 17/04/2020

Revize / Revised: 11/08/2020

Kabul / Accepted: 22/08/2020

ÖZ

Bu çalışmada, kobalt katkılı kalsiyum manganez oksit numunelerinin faz bileşimleri, kristal yapıları, yüzey morfolojileri ve termal özellikleri karakterize edildi. Co miktarının bu oksit yapı üzerindeki etkileri belirlendi. Xışını kırınımı (XRD) sonuçları, kalsiyum manganez oksit fazlarının oluşumuna işaret etmektedir. Fourier dönüşümlü kızılötesi (FTIR) analizleri, her bir numune için peroksit yapısının oluşumunu doğrulamaktadır. Termal analiz sonuçları, üretilen numunelerin termal olarak kararlı olduklarını göstermektedir. Numunelerin taramalı elektron mikroskobu (SEM) gözlemleri ve enerji dağılımlı X-ışını (EDX) analizleri, Co katkısının morfolojiye etki ettiğini ve kalsiyum manganez oksit yapıya nüfuz ettiğini desteklemektedir.

Anahtar Kelimeler- Kalsiyum Manganez Oksit, X-Işını Kırınımı (XRD), Morfoloji, Co Katkılama

1*Sorumlu yazar iletişim: tankut.ates@ozal.edu.tr (https://orcid.org/0000-0002-4519-2953)

Mühendislik Temel Bilimleri Bölümü, Mühendislik ve Doğa Bilimleri Fakültesi, Turgut Özal Üniversitesi, 44210 Malatya

2İletişim: suleyman.koytepe@inonu.edu.tr(https://orcid.org/0000-0002-4788-278X)

Kimya Bölümü, Fen-Edebiyat Fakültesi, Inönü Üniversitesi, 44280 Malatya

3̇letișim:omerkaygili@yahoo.com (https://orcid.org/0000-0002-2321-1455)

Fizik Bölümü, Fen Fakültesi, Fırat Üniversitesi, 23119 Elazığ 


\title{
Synthesis and Characterization of Cobalt-Doped Calcium Manganese Oxide Samples
}

\begin{abstract}
In this study, the phase compositions, crystal structures, surface morphologies, and thermal properties of cobaltdoped calcium manganese oxide samples were characterized. The effects the amount of Co on this oxide structure were determined. X-ray diffraction (XRD) analysis results indicate the formation of the calcium manganese oxide phases. Fourier transform infrared (FTIR) analyses verify the formation of the perovskite structure for each sample. Thermal analysis results show that the as-produced samples are thermally stable. The scanning electron microscope (SEM) observations and energy dispersive X-ray (EDX) analyses support that the Co-doping affects the morphology and influences the calcium manganese oxide structure.
\end{abstract}

Keywords-Calcium Manganese Oxide, X-Ray Diffraction (XRD), Morphology, Co-Doping 


\section{I.GİRIŞ}

Peroksit minerali ilk olarak Rusya'da Ural dağlarını eteklerinde $\mathrm{CaTiO}_{3}$ (kalsiyum titanyum oksit) minerali şeklinde tespit edildikten sonra, zamanla bu isim, benzer kristal yapıdaki daha geniş malzeme grubu olarak genelleştirilmiştir. Peroksit için $\mathrm{ABC}_{3}$ formülasyonu kullanılmaktadır. Peroksit malzemelerin ideal kristal yapısı, kübik simetriye uygundur [1,2].

A ve B katyonları farklı grupları temsil etmek üzere, $\mathrm{C}$ anyonu olarak oksijen kullanılmasıyla $\mathrm{ABO}_{3}$ peroksit oksit yapısı karşımıza çıkar. $\mathrm{ABO}_{3}$ peroksit oksit yapıda genellikle, A katyonu nadir toprak elementlerinden ( $\mathrm{La}, \mathrm{Pr} v \mathrm{vb}$.), alkali veya toprak alkali metallerden ( $\mathrm{Ca}, \mathrm{Sr}, \mathrm{Ba} \mathrm{vb}$.$) , B katyonları ise geçiş$ metallerinden (Mn, Co vb.) seçilebilir [1-4].

Peroksit oksitlerden, Kalsiyum Manganez Oksitlerin $\left(\mathrm{CaMnO}_{3}\right)$ yapısı, köşe paylaşımlı oktahedron şeklindedir. Oktahedronun merkezinde daha küçük iyon yarıçaplı Mn katyonu köşelerdeki 6 oksijen anyonları ile çevrilidir. Daha büyük iyon yarıçaplı Ca iyonu ise 12 oksijen anyonu ile çevrilidir [1-4]. Bu kristal yapı malzemeye, fiziksel ve kimyasal özelliklerini önemli ölçüde değiştirebilme imkânı sunan, değişik değerlik ve boyutlarda çok farklı katkılama kabiliyeti sunar [5,6]. Katkı maddesi, yarıçapına bağlı olarak A bölgesini, B bölgesini ya da A ve B bölgelerinin ikisini de işgal edecektir. Tipik olarak, daha büyük katkı atomları A bölgelerini işgal ederken, daha küçük katyonlar B bölgelerini tercih eder [7].

Manganez oksit peroksitlerin, çok iyi manyetorezistans özelliği, iletkenlik, manyetik, elektronik ve termoelektrik özelliklerinden dolayı, mikroelektronik uygulamalarda, orta derece manyetik alanlar için Hall probları ve manyetik disklerdeki okuma kafaları, manyetorezistans dönüştürücü ve sensörler (manyetik alan sensörleri) gibi uygulama alanları vardır [3,8,9]. Ayrıca $\mathrm{CaMnO}_{3}$ peroksitler, iyi elektriksel ve manyetik özelliklerinden dolayı, kimyasal uygulamalar arasında, katı oksit yakıt hücre elektrotları, otomobil egzoz katalizörleri için düşünülmüştür $[3,9,10]$.

Son yıllarda peroksit malzemelerin fotovoltaik özelliklerinden dolayı, günümüz güneş enerji teknolojilerine göre \%20 daha fazla verim sağlayan bu malzemeler ilgi uyandırmıştır. Fotovoltaik cihazlarda emici katman olarak peroksit malzemelerin kullanımı, yüksek emilim katsayısı, uzun difüzyon uzunluğu, 1,4-3,0 $\mathrm{eV}$ arası ayarlanabilir bant boşluğu gibi fizikokimyasal özelliklerinden dolayı avantajlıdır [11].

Artan enerji krizi, fosil yakıt kullanımını azaltmak ve çevresel olumsuz etkileri azaltmak için yeni enerji çözümlerine ihtiyaç vardır [12]. Özellikle endüstriyel alanlardaki atık ısı enerjisi ve otomobillerin motorlarındaki kayıp 1S1 enerjisi, jeotermal 1S1, güneş 1Sısı gibi enerji kayıplarını ortadan kaldırıp yenilenebilir şekilde dönüştürmek ve ayrıca çevreye zararlı sera gazını azaltmak için umut verici bir yöntem termoelektrik (TE) cihazlardır [12-14]. TE cihazları kayıp durumundaki bu atık 1s1 enerjisini doğrudan elektrik enerjisine dönüştürebilmektedir [14-17]. N-tipi oksit yariletken $\mathrm{CaMnO}_{3}$ malzemelerin, geleneksel TE malzemelerinin sahip olduğu yüksek Seebeck katsayısı, düşük elektriksel direnç ve toplam termal iletkenlik özelliklerine [5,13,15,18-20] sahip olmasının yanında, çevreye duyarlı (toksik değil), yüksek termal kararlılık, hammaddelerin ucuzluğu ve kolay imalatı gibi olağanüstü avantajlara sahip olması TE malzemeler olarak kullanımını desteklemektedir [5,12-16,21].

$\mathrm{Bu}$ avantajlarının yanında $\mathrm{CaMnO}_{3}$ malzemeler tüm oksit malzemelerdeki düşük enerji dönüşüm verimliliğine sahiptir $[12,16]$. Ayrıca düşük mekanik mukavemet, $900{ }^{\circ} \mathrm{C}$ civarında meydana gelen faz modifikasyonları olasılığı, oksijen açısından zengin alanların ortaya çıkması diğer olumsuzlukları olarak siralanabilir [12].

Literatürde yapılan çalışmalar katkılama işleminin çalışılan malzemenin elektronik, yapısal ve optik özelliklerini geliştirerek, istenilen özellikte bir malzeme elde etmemize yardımcı olmaktadır [22,23].Örneğin, $\mathrm{CaMnO}_{3}$ üzerine yapılan çalışmalarda, Zhang ve diğerleri [5], Sr katkısının $\mathrm{CaMnO}_{3}$ sisteminin TE özelliklerini geliştirebileceğini rapor etmişlerdir. Zhan ve diğerleri [24], Dy katkısının $\mathrm{CaMnO}_{3}$ yapısına eklenmesi ile elektriksel iletkenliğin geliştirilebilir olduğunu belirtmişlerdir. Liu ve diğerleri [14] çalışmalarında nadir toprak elementi Pr ve alkali toprak elementi Sr katkılamasının yapıdaki gözenekliliği azalttığı, elektriksel iletkenliği artırdığı, birlikte katkılama ile toplam termal iletkenliğin daha da düşürülebileceğini ve birlikte katkılama işleminin malzemenin TE performansını iyileştirmede alternatif olarak kullanılabileceğini belirtmişlerdir. 
Ayrıca, Park ve diğerleri [25] yaptıkları çalışmada $\mathrm{CaMnO}_{3}$ yapısına sırası ile Bi ve Nb’nin Ca bölgesine ve Mn bölgesine eşzamanlı olarak katkılaması ile elektriksel iletkenliğin artırıldığı ve TE özelliklerinin geliştirildiğinin gözlendiğini, bunlara ek olarak artan sıcaklıkla Seebeck katsayısının artma ve elektriksel iletkenliğin düşme eğiliminde olduğunu belirtmişlerdir.

\section{II.MATERYAL VE YÖNTEM}

Numunelerin sentezi esnasında Sigma-Aldrich firmasından satın alınan kalsiyum nitrat tetrahidrat, manganez nitrat tetrahidrat ve kobalt nitrat tetrahidrat kullanılmıştır. Numunelerin sentezi şu şekilde gerçekleştirilmiştir: $100 \mathrm{~mL}$ 'lik $20 \mathrm{mmol}$ kalsiyum nitrat tetrahidrat çözeltisi (saf suda), yine $100 \mathrm{~mL}$ 'lik (20-x) mmol manganez nitrat tetrahidrat ve $x$ mmol kobalt nitrat tetrahidrat çözeltisi (saf suda) içerisinde dökülerek yeni bir çözelti elde edilmiştir. Burada x değeri 0,2, 4 ve 6 alınmak suretiyle dört farklı numune üretilmiş olup, üretilen bu numuneler de sirasıyla CMO1, CMO2, CMO3 ve CMO4 şeklinde isimlendirilmiştir. Sonrasında elde edilen son çözelti, ısıtıcılı bir manyetik karıştırıcı yardımıyla $75{ }^{\circ} \mathrm{C}$ sıcaklıkta 2,5 saat karıştırıldı, $130{ }^{\circ} \mathrm{C}$ sıcaklıkta 24 saat kurutuldu ve sonrasında kül firını içerisinde $1050{ }^{\circ} \mathrm{C}$ 'de 1,5 saat 1 sıl işleme tabi tutularak kobalt katkılı kalsiyum manganez oksitler üretildi.

X-1şını kırınımı (XRD) analizleri Bruker D8 Advance cihazıyla ve Fourier dönüşümlü kızılötesi (FTIR) spektrumları Perkin Elmer Spectrum two spektrofotometresiyle $400-4000 \mathrm{~cm}^{-1}$ dalga sayısı aralığında kaydedildi. Morfolojik gözlemler Röntech xflash model enerji dağılımlı X-ışını (EDX) analizörüne sahip LEO EVO 40xVP model taramalı elektron mikroskobu ile gerçekleştirildi.

Çalışma kapsamında sentezlenen kobalt katkılı kalsiyum manganez oksit numunelerinin termal özellikleri Shimadzu TGA-50 ve Shimadzu DTA-50 cihazları ile belirlendi. DTA analizleri $10{ }^{\circ} \mathrm{C} / \mathrm{dk}$. $1 \mathrm{sitma}$ hızında ve $50 \mathrm{~mL} / \mathrm{dk}$. akış hızındaki dinamik azot atmosfer altında gerçekleştirildi. $\mathrm{Bu}$ analizlerde $\alpha-\mathrm{Al}_{2} \mathrm{O}_{3}$ referans malzemesi olarak kullanılmıştır. TGA analizleri ise $30{ }^{\circ} \mathrm{C}-1000{ }^{\circ} \mathrm{C}$ aralığında $10{ }^{\circ} \mathrm{C} / \mathrm{dk}$.'lık bir 1 sıtma hızı ile belirlendi. TGA analizleri $10 \mathrm{mg}$ numune kullanılarak $50 \mathrm{~mL} / \mathrm{dk}$. akış hızındaki dinamik azot atmosfer altında gerçekleştirilmiştir.

\section{III.BULGULAR VE TARTIŞMA}

\section{A. X-Işııı Kırınımı (XRD) Analizi}

Katkısız ve Co-katkılı kalsiyum manganez oksit numunelere ait X-ışını kırınımı (XRD) desenleri Şekil 1 'de verilmiştir. Şekilden de açıkça görülebileceği gibi Co katkısı ve bunun miktarıyla pik şiddetlerinde belirgin değişimler meydana gelmektedir. Şekil 1'de verilen XRD desenlerinde $\mathrm{Ca}_{2} \mathrm{Mn}_{2} \mathrm{O}_{5}$ (JCPDS PDF no: 36-0531, ortorombik), $\mathrm{CaMnO}_{3}$ (JCPDS PDF no: 76-1132), $\mathrm{CaO}$ (JCPDS PDF no: 37-1497, kübik) ve $\mathrm{Ca}_{3} \mathrm{CoMnO}_{6}$ (JCPDS PDF no: 51-1776, trigonal) fazlarına ait pikler görülmektedir. Tüm numuneler için gözlemlenen bu piklerin yüzde bileşimleri Tablo 1 'de verildiği gibidir. Co katkısı ile $\mathrm{Ca}_{3} \mathrm{CoMnO}_{6}$ fazının oluşumu gözlenmektedir. Co katkısı arttıkça $\mathrm{CaO}$ fazının giderek gözden kaybolmaya başladığı görülmektedir. Yine artan Co miktarıyla $\mathrm{CaMnO}_{3}$ fazının baskınlığının arttığı görülmektedir. Ayrıca, pik şiddetlerindeki değişim ve gözlemlenen faz dönüşümleri, Co’’n yapı içerisine nüfuz ettiğinin bir göstergesidir. 


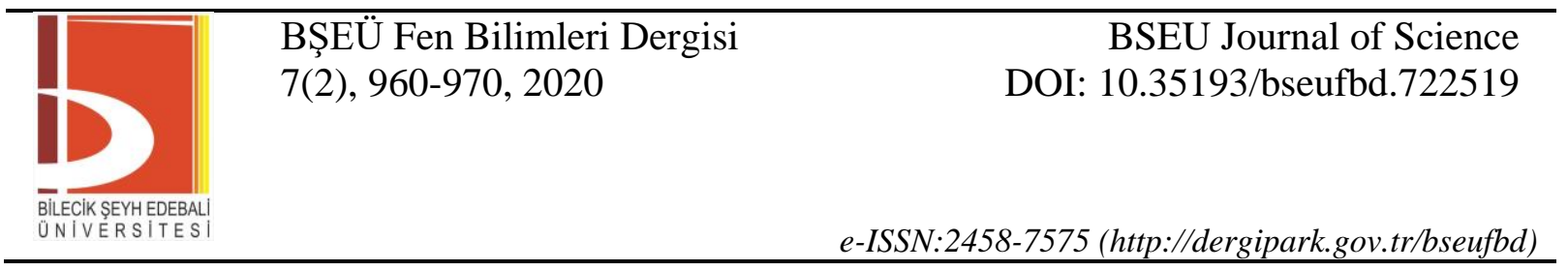

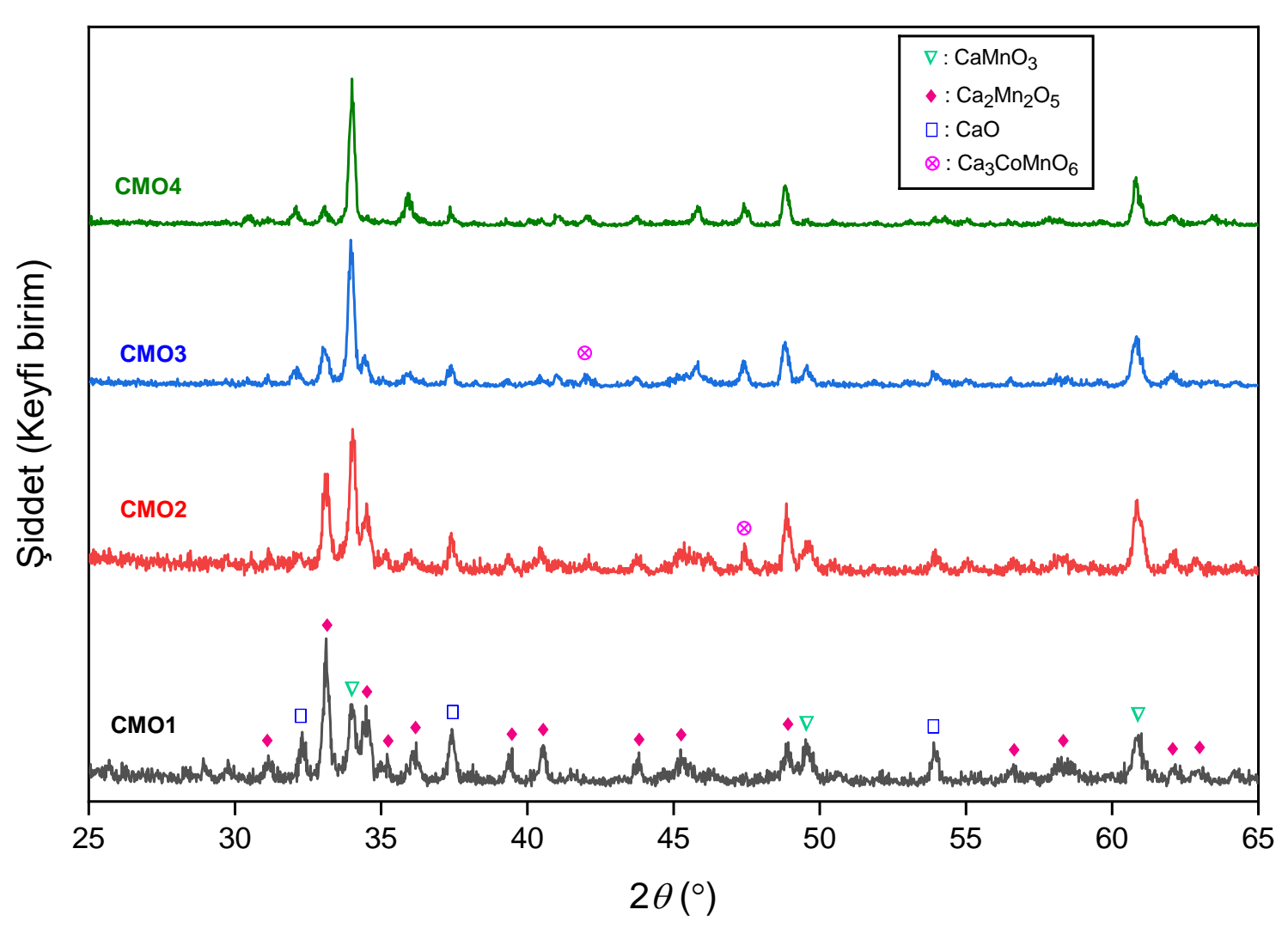

Şekil 1. CMO1, CMO2, CMO3 ve CMO4 numunelerine ait XRD desenleri

Kristal büyüklüklerinin $(D)$ hesaplanması Scherrer denklemi kullanılarak gerçekleştirildi [26].

$$
D=\frac{0.9 \lambda}{\beta \cos \theta}
$$

Burada $\lambda$ dalga boyu, $\beta$ yarı maksimumdaki tam pik genişliği ve $\theta$ Bragg açısıdır. Numunelerin kristal büyüklükleri CMO1, CMO2, CMO3 ve CMO4 için sırasıyla 40,06 nm, 31,85 nm, 34,34 nm ve 39,21 nm olarak hesaplanmıştır. Bu sonuçlar, Co katkısının kristal büyüklüğü üzerine etki ettiğini destekler niteliktedir.

Tablo 1. Kalsiyum manganez oksit numunelerine ait faz bileşimleri

\begin{tabular}{ccccc}
\hline Numune & $\mathrm{Ca}_{2} \mathbf{M n}_{2} \mathbf{O}_{\mathbf{5}}(\boldsymbol{\%})$ & $\mathbf{C a M n O}_{\mathbf{3}}(\boldsymbol{\%})$ & $\mathbf{C a O}(\%)$ & $\mathrm{Ca}_{3} \mathrm{CoMnO}_{\mathbf{6}}(\boldsymbol{\%})$ \\
\hline CMO1 & 79,81 & 11,29 & 8,90 & - \\
$\mathrm{CMO} 2$ & 71,34 & 18,11 & 8,37 & 2,18 \\
$\mathrm{CMO3}$ & 54,28 & 31,70 & 6,79 & 7,23 \\
$\mathrm{CMO} 4$ & 25,03 & 60,31 & 1,55 & 13,11 \\
\hline
\end{tabular}

\section{B. FTIR Analiz Sonuçları}

Sentezlenen farklı oranlarda kobalt katkılı kalsiyum manganez oksit numunelerinin FTIR spektrumları Şekil 2'de gösterilmiştir. Bu analizlerde iki farklı spektrum yapısı görülmektedir. CMO1 yapısının analizinde 
oldukça şiddetli M-O-M gerilme pikleri yaklaşık $400 \mathrm{~cm}^{-1}$ ve $510 \mathrm{~cm}^{-1}$, M-O veya M-O-M gerilme piki ise MnO bağından kaynaklı olarak $\sim 590 \mathrm{~cm}^{-1}$ 'de görülmektedir [27]. Ayrıca $1045 \mathrm{~cm}^{-1}$ de $\mathrm{M}-\mathrm{O}(\mathrm{M}=\mathrm{Ca}, \mathrm{Mn})$ yapısından kaynaklanan zayıf bir pik görülmektedir [28]. Her üç pik CMO2, CMO3 ve CMO4 yapılarında benzer dalga sayısında görülmektedir. Ancak bu piklere ek olarak $510 \mathrm{~cm}^{-1}$, deki pik yapısında Co katkılaması ile bir değişim olmuştur. Bu pikin değeri daha güçlü olan $\mathrm{Co}-\mathrm{O}$ bağından kaynaklı olarak daha düşük dalga sayısına kaymıştır ve şiddeti artmıştır. Şekil 2'deki $400 \mathrm{~cm}^{-1}-600 \mathrm{~cm}^{-1}$ arasındaki pikler istenen peroksit yapısını doğrular niteliktedir [29].

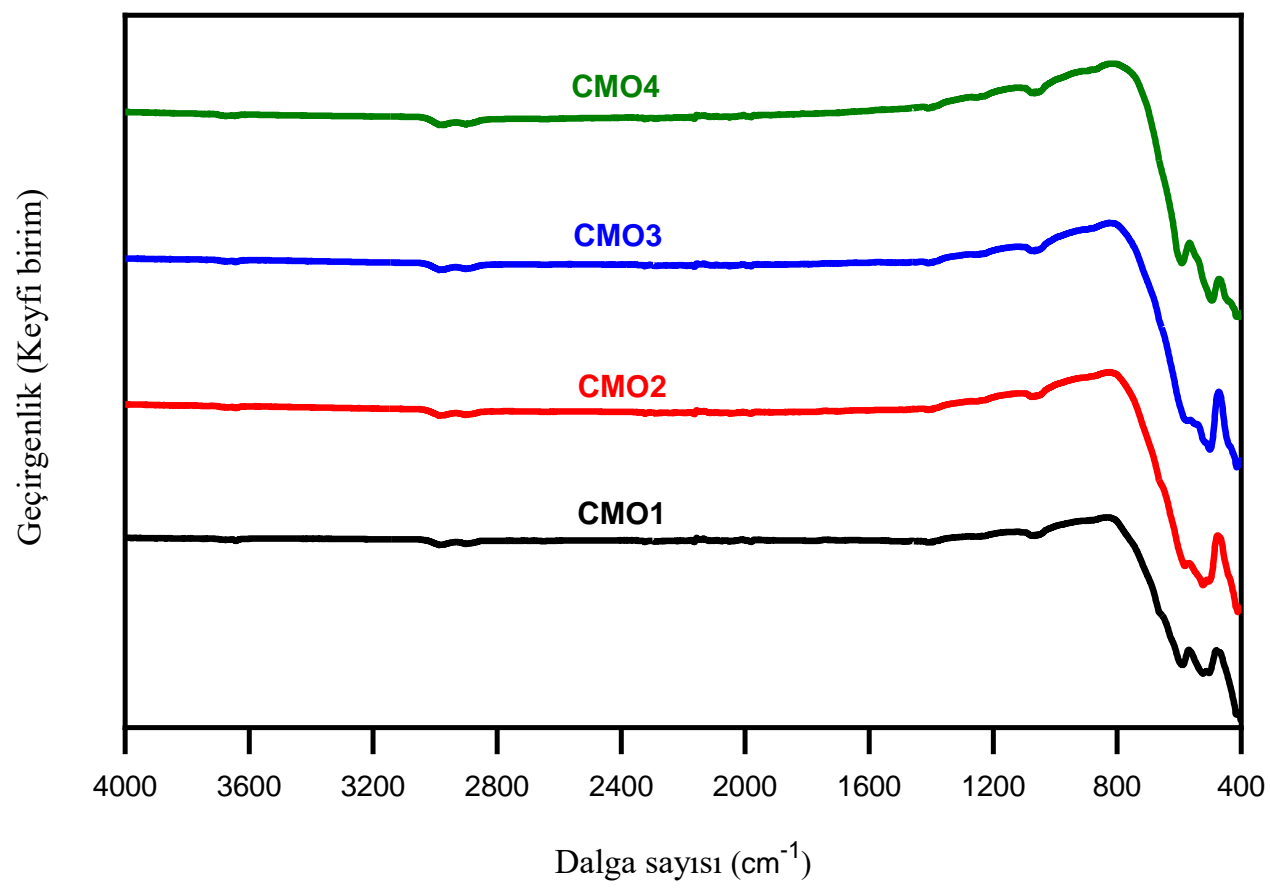

Şekil 2. CMO1, CMO2, CMO3 ve CMO4 numunelerine ait FTIR spektrumları

\section{Morfolojik Incelemeler}

Sentezlenen CMO1, CMO2, CMO3 ve CMO4 numunelerine ait SEM görüntüleri ve bu görüntü alınan numunelere ait EDX spektrumları sonuçları Şekil 3'te verilmiştir. 


\begin{tabular}{|c|c|c|}
\hline & $\begin{array}{l}\text { BŞEÜ Fen Bilimleri Dergisi } \\
7(2), 960-970,2020\end{array}$ & $\begin{array}{r}\text { BSEU Journal of Science } \\
\text { DOI: } 10.35193 / \text { bseufbd.722519 }\end{array}$ \\
\hline & & 58-7575 (http://dergipark.gov.tr/bseufbd) \\
\hline
\end{tabular}
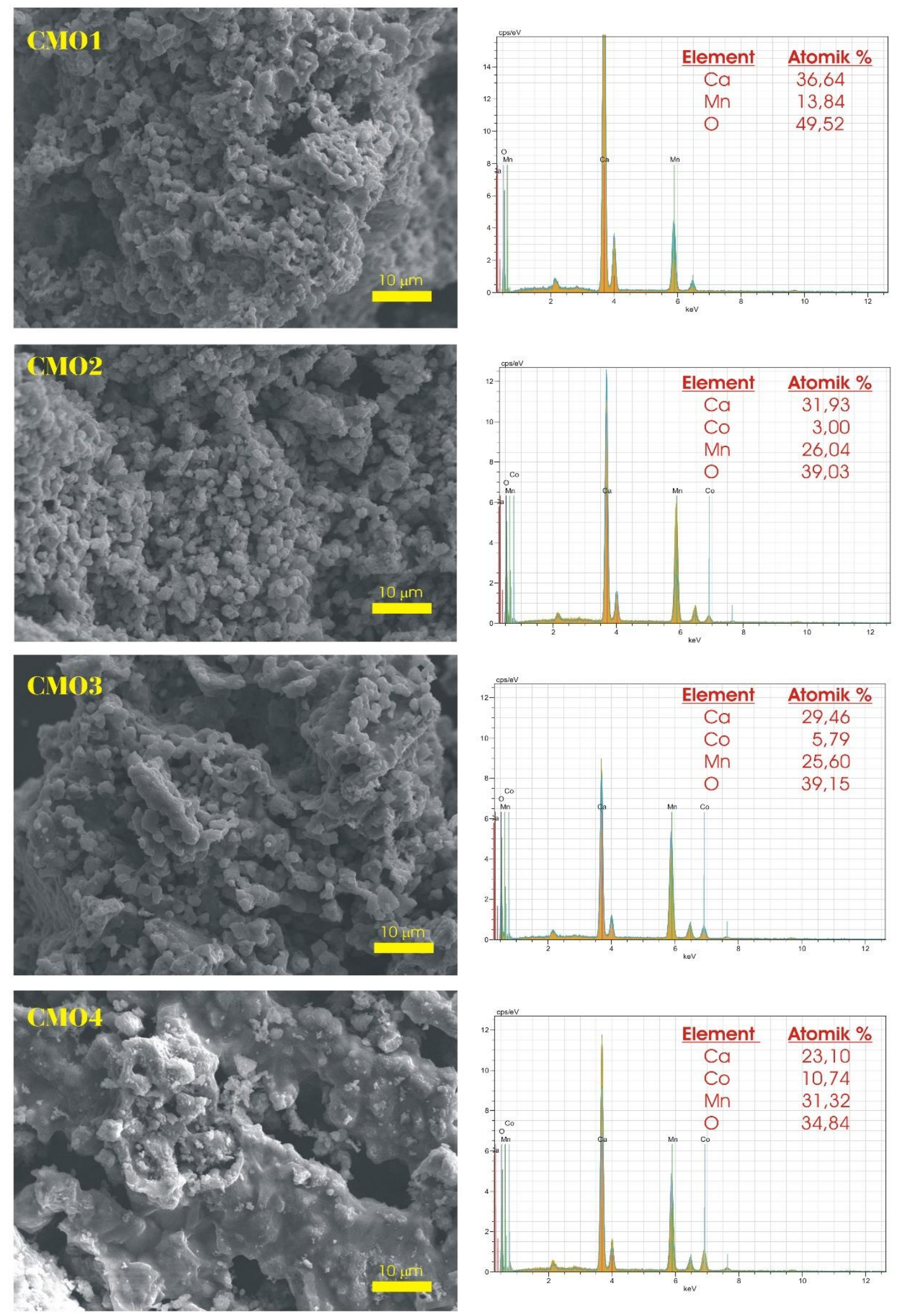

Şekil 3. CMO1, CMO2, CMO3 ve CMO4 numunelerine ait SEM resimleri ve EDX görüntüleri. 
Şekil 3'deki CMO1'in SEM görüntüleri incelendiğinde, mikropartiküler parçacık yapısı gözlenmektedir. Kobalt katkılaması ile yapıda morfolojik bir değişim görülmekte olup öncelikle parçacık boyutu büyümekte daha sonra ise CMO4 numunesinde ise monolitik gözenekli bir yapı görülmüştür.

EDX spektrumları, üretilen katkısız $\mathrm{CaMnO}_{3}$ numunesi (CMO1) ve farklı oranlarda kobalt katkılanmış CMO2, CMO3 ile CMO4 numunelerinin elementel içeriğini ve kobalt katkı oranını belirlemek için gerçekleştirilmiştir. Şekil 3'deki Saf $\mathrm{CaMnO}_{3}(\mathrm{CMO} 1)$ yapısının EDX spektrumunda, Ca, Mn ve O pikleri açıkça görülür. Ca piki, 0,34 (L $\alpha)$ ve 3,69 $(\mathrm{K} \alpha) \mathrm{keV}$ 'de görülür. CMO1 yapısının EDX spektrumundaki Mn'a ait 0,64

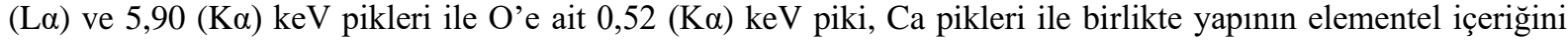
doğrulamaktadır. CMO2, CMO3 ile CMO4 numunelerinin EDX spektrumlarında $\mathrm{Ca}$, Mn ve O piklerine ek olarak yapıya katkılanan kobaltın pikleri $0,77(\mathrm{~L} \alpha)$ ve $6,93(\mathrm{~K} \alpha) \mathrm{keV}$ değerinde gözlenmiştir. Katkılama miktarına bağlı olarak elementel bulunma oranlarına bakıldığında CMO2'de \%3,00, CMO3'te \%5,79 ve CMO4'te \%10,74 oranında kobalt bulunduğu görülmektedir.

\section{Termal Analiz Sonuçları}

Üretilen farklı oranlarda kobalt katkılı kalsiyum manganez oksit numunelerinin DTA ve TGA termogramları sırasıyla Şekil 4 ve Şekil 5'te verildiği gibidir. Şekil 4'teki DTA termogramında CMO1 numunesinde yaklaşık $820{ }^{\circ} \mathrm{C}$ 'de bir faz geçişi görülmüştür. Literatürle uyumlu olarak bu faz geçişi ortorombik $\mathrm{CaMnO}_{3}$ 'ün kübik bir faza dönüşümünden kaynaklanmaktadır [30-31]. CMO2, CMO3 ve CMO4 numunelerinin analizinde $780-850{ }^{\circ} \mathrm{C}$ arasında bu faz geçişi görülmekte olup kobaltın katkılaması ile $\mathrm{CaMnO}_{3}$ 'ün oranının azalmasından kaynaklı olarak pik şiddeti azalmaktadır. Ayrıca kobalt katkılaması ile faz geçiş piki daha düşük sıcaklık değerine $\left(805^{\circ} \mathrm{C}\right)$ doğru kaymaktadır [30]. Bu sonuç EDX analizi ile beraber istenilen oranda Co katkılamasının gerçekleştiğini doğrular niteliktedir.

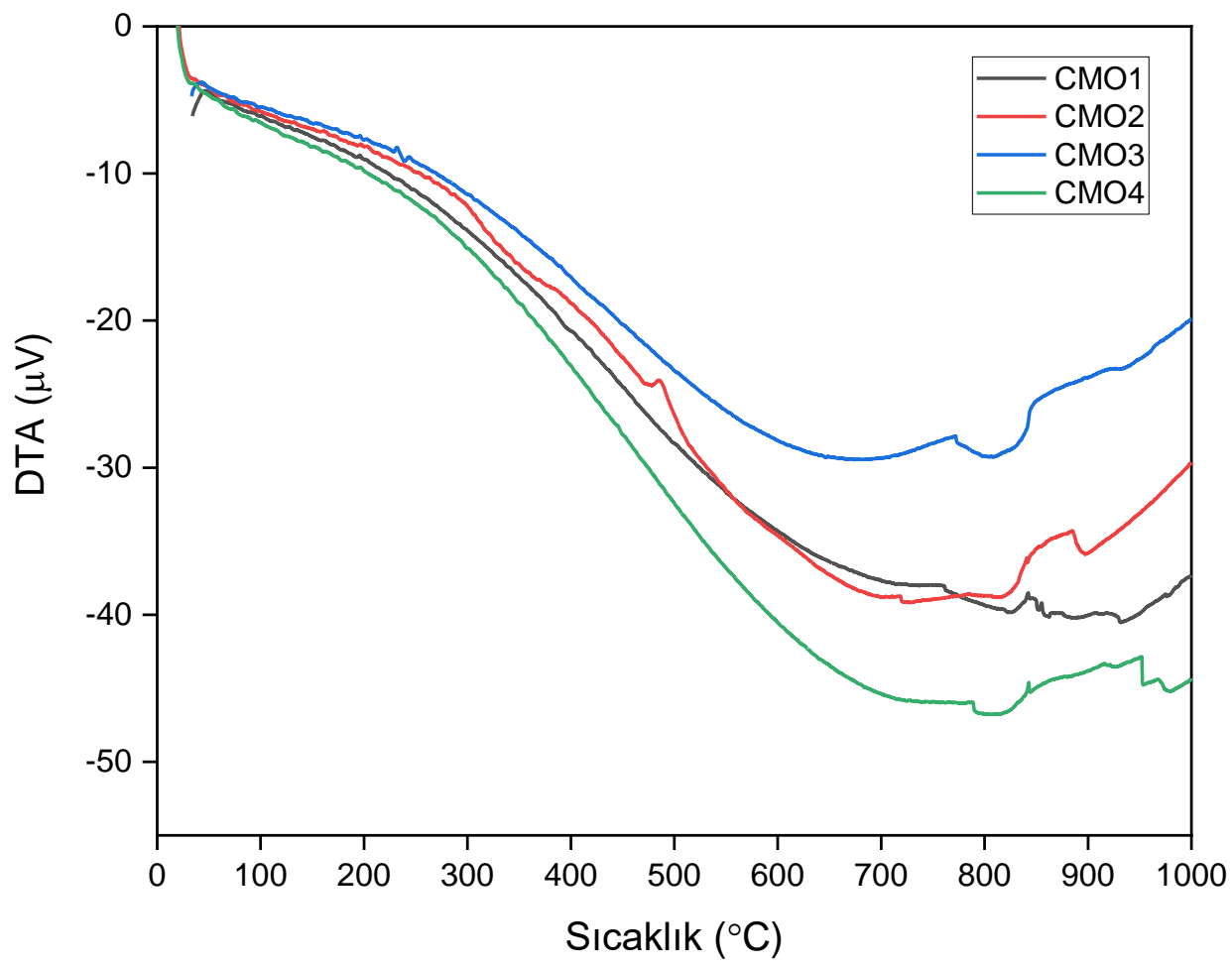

Şekil 4. CMO1, CMO2, CMO3 ve CMO4 numunelerine ait DTA termogramları. 


\begin{tabular}{|c|c|c|}
\hline & $\begin{array}{l}\text { BŞEÜ Fen Bilimleri Dergisi } \\
7(2), 960-970,2020\end{array}$ & $\begin{array}{r}\text { BSEU Journal of Science } \\
\text { DOI: } 10.35193 / \text { bseufbd.722519 }\end{array}$ \\
\hline & & 88-7575 (http://dergipark.gov.tr/bseufbd) \\
\hline
\end{tabular}

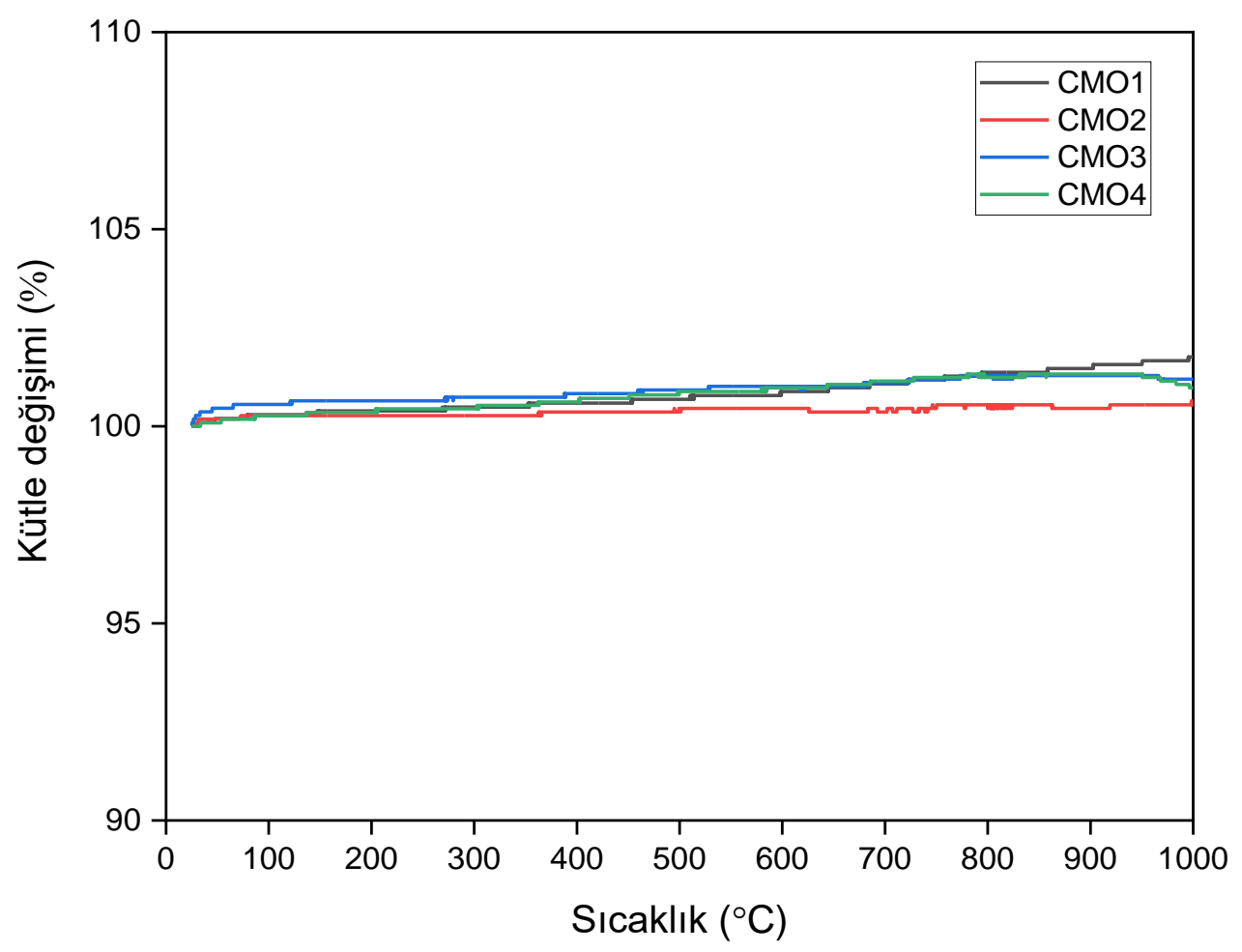

Şekil 5. CMO1, CMO2, CMO3 ve CMO4 numunelerine ait TGA termogramları.

Şekil 5'deki TGA termogramlarında ise belirgin ve net kütle değişimleri görülmemiş̧ir. Bu sonuç 1050 ${ }^{\circ} \mathrm{C}$ 'de 1,5 saat 1 sıl işlem sonrasında hedeflenen $\mathrm{CaMnO}_{3}$ ve kobalt katkılı $\mathrm{CaMnO}_{3}$ yapılarının termal ve yapısal kararlı olarak elde edildiğini göstermektedir.

\section{IV.SONUÇLAR}

$\mathrm{Bu}$ çalışmada Co katkısının kalsiyum manganez oksit yapıların kristal yapısı, termal özellikleri ve morfolojisi üzerine etkileri araştırılmıştır. Bu kapsamda, bir adet katkısız ve üç adet artan Co içeriğine sahip numune üretilmiş ve karakterize edilmiştir. XRD sonuçları, kristal büyüklüğünün ve faz bileşiminin Co miktarından belirgin bir biçimde etkilendiğini göstermektedir. FTIR analizleri peroksit yapı oluşumunu doğrular niteliktedir. DTA ve TGA sonuçları, üretilen numunelerin termal olarak kararlı bir yapıya sahip olmalarını göstermesinin yanı sıra, Co katkısının kalsiyum manganez oksit yapının termal özellikleri üzerine etki ettiğini desteklemektedir. SEM gözlemleri, morfolojinin Co katkısından ve bu katkılanan elementin miktarından etkilendiğini göstermektedir. EDX analiz sonuçları, üretilen numunelerin herhangi bir safsızlık içermediğini ve Co elementinin kalsiyum manganez oksit yapı içerisine nüfuz ettiğini işaret etmektedir. Elde edilen tüm analiz sonuçlarına bir bütün halinde bakacak olursak; Co katkılaması kullanılmak suretiyle kalsiyum manganez oksit yapıların kristal büyüklükleri, faz bileşimleri ve morfolojileri kontrol edilebilir.

\section{KAYNAKLAR}

[1] Erkişi, A. (2015). Bazı ABO 3 Tipi Perovskite Yapıdaki Oksit Kristallerin Yapısal, Mekanik, Elektronik ve Manyetik Özelliklerinin Yoğunluk Fonksiyoneli Teorisi ile Incelenmesi. Doktora Tezi, Kırıkkale Üniversitesi, Fen Bilimleri Enstitüsü, Kırıkkale.

[2] Coşkun, F.M. (2016). Katkllı Perovskit Güneş Pillerinin Üretimi ve Fotovoltaik Karakterizasyonu.Doktora Tezi, Atatürk Üniversitesi, Fen Bilimleri Enstitüsü, Erzurum. 
[3] Paszkowicz, W., Piętosa, J., Woodley, S.M., Dłużewski, P.A., Kozłowski, M., \& Martin, C.(2010). Lattice parameters and orthorhombic distortion of $\mathrm{CaMnO}_{3}$.Powder Diffraction, 25(1), 46-59.

[4] Pektaş, M. (2011). $\mathrm{La}_{0.67} \mathrm{Ca}_{0.33} \mathrm{MnO}_{3}$ Alaşımında Ag katkılamanın İletkenlik ve Manyetik Özellikleri Üzerine Etkisi. Yüksek Lisans Tezi, İnönü Üniversitesi, Fen Bilimleri Enstitüsü, Malatya.

[5] Zhang, F.P., Zhang, X., Lu, Q.M., Zhang, J.X., Liu,Y.Q., Fan,R.F.,\&Zhang, G.Z.(2011). Doping induced electronic structure and estimated thermoelectric properties of $\mathrm{CaMnO}_{3}$ system.Physica B, 406, 1258-1262.

[6] Zhang, F.P., Zhang, X., Lu,Q.M., Zhang,J.X., \& Liu,Y.Q. (2011). Electronic structure and thermal properties of doped $\mathrm{CaMnO}_{3}$ systems.Journal of Alloys and Compounds, 509, 4171-4175.

[7] Dukic, J., Boskovic, S.,\& Matovic, B.(2009). Crystal structure of Ce-doped $\mathrm{CaMnO}_{3}$ perovskite.Ceramics International, 35, 787-790.

[8] Wang, K., Jiang, W., Chen, J.N.,\& Huang, J. Q.(2016). Study of the electronic structure and halfmetallicity of $\mathrm{CaMnO}_{3} / \mathrm{BaTiO}_{3}$ superlattice.Superlattices and Microstructures, 97, 116-124.

[9] Hamdad, N.,\& Bouhafs, B.(2010). Theoretical analysis of the spin effect on the electronic and magnetic properties of the calcium manganese oxide $\mathrm{CaMnO}_{3}$ : GGA+U calculation.Physica B, 405, 4595-4606.

[10] Boskovic, S., Dukic, J., Matovic, B., Zivkovic, L. J., Vlajic, M.,\& Krstic, V.(2008). Nanopowders properties and sintering of $\mathrm{CaMnO}_{3}$ solid solutions.Journal of Alloys and Compounds, 463, 282-287.

[11] Pandey, K., Singh, D., Gupta, S.K., Yadav, P., Sonvane, Y., Lukačević, I., Kumar, M., Kumar, M.,\& Ahuja, R.(2018). Improving electron transport in the hybrid perovskite solar cells using $\mathrm{CaMnO}_{3}$-based buffer layer.Nano Energy, 45, 287-297.

[12] Ferreira, N.M., Neves, N.R., Ferro, M.C., Torres, M.A., Madre, M.A., Costa, F.M., Sotelo, A.,\& Kovalevsky, A. V.(2019). Growth rate effects on the thermoelectric performance of $\mathrm{CaMnO}_{3}$-based ceramics.Journal of the European Ceramic Society, 39, 4184-4188.

[13] Berbeth Mary, S., Francis, M., Sathe, V.G., Ganesan, V.,\& Leo Rajesh, A.(2019). Enhanced thermoelectric property of nanostructured $\mathrm{CaMnO}_{3}$ by sol-gel hydrothermal method.Physica B: Physics of Condensed Matter, 575, 411707.

[14] Liu, K.K., Liu, Z.Y., Zhang, F.P., Zhang, J.X., Yang, X.Y., Zhang, J.W., Shi, J.L., Ren, G., He, T.W.,\& Duan, J. J.(2019). Improved thermoelectric performance in $\mathrm{Pr}$ and $\mathrm{Sr} \mathrm{Co}$-doped $\mathrm{CaMnO}_{3}$ materials.Journal of Alloys and Compounds, 808, 151476.

[15] Zhang, F.P., Lu, Q.M., Zhang, X.,\& Zhang, J. X.(2013). Electrical transport properties of $\mathrm{CaMnO}_{3}$ thermoelectric compound: a theoretical study.Journal of Physics and Chemistry of Solids, 74, 1859-1864.

[16] Baranovskiy, A., Graff, A., Klose, J., Mayer, J.,\& Amouyal, Y.(2018). On the origin of vibrational properties of calcium manganate based thermoelectric compounds.Nano Energy, 47, 451-462.

[17] Baranovskiy, A.,\& Amouyal, Y.(2016). Structural stability of calcium-manganate based $\mathrm{CaO}(\mathrm{CaMnO})_{\mathrm{m}}$ $(\mathrm{m}=1,2,3, \infty)$ compounds for thermoelectric applications.Journal of Alloys and Compounds, 687, 562569.

[18] Phaga, P., Vora-Ud, A.,\& Seetawan, T.(2012). Invention of Low Cost Thermoelectric Generators.Procedia Engineering, 32, 1050-1053.

[19] Nakhowong, R.(2016). Preparation and characterization of calcium manganese oxide $\left(\mathrm{CaMnO}_{3}\right)$ nanofibers by electrospinning.Materials Letters, 163, 222-225. 
[20] Kabir, R., Tian, R., Zhang, T., Donelson, R., Teck Tan, T.,\& Li, S.(2015). Role of Bi doping in thermoelectric properties of $\mathrm{CaMnO}_{3}$.Journal of Alloys and Compounds, 628, 347-351.

[21] Zhu, Y., Wang, C., Wang, H., Su, W., Liu, J.,\& Li, J.(2014). Influence of Dy/Bi dual doping on thermoelectric performance of $\mathrm{CaMnO}_{3}$ ceramics.Materials Chemistry and Physics, 144, 385-389.

[22] Kara, F., Kurban, M., \&Coşkun, B. (2020). Evaluation of electronic transport and optical response of twodimensional Fe-doped $\mathrm{TiO}_{2}$ thin films for photodetector applications.Optik, 210, 164605.

[23] Kurban, M. (2018) Electronic structure, optical and structural properties of $\mathrm{Si}, \mathrm{Ni}, \mathrm{B}$ and N-doped a carbon nanotube: DFT study.Optik, 172, 295-301.

[24] Zhan, B., Lan, J., Liu, Y., Lin, Y., Shen, Y.,\& Nan, C.(2014). High Temperature Thermoelectric Properties of Dy-doped $\mathrm{CaMnO}_{3}$ Ceramics.J. Mater. Sci. Technol., 30(8), 821-825.

[25] Park, J.W., Kwak, D.H., Yoon, S.H.,\& Choi, S. C.(2009). Thermoelectric properties of Bi, Nb cosubstituted $\mathrm{CaMnO}_{3}$ at high temperature.Journal of Alloys and Compounds, 487, 550-555.

[26] Cullity, B. D. (1978).Elements of X-ray Diffraction $2^{\text {nd }}$ Ed. Addison-Wesley Publishing Company, Massachusetts, 102.

[27] Nandan, K. R., \& Ruban Kumar, A. (2019). Structural and electrical properties ofCa $\mathrm{a}_{0.9} \mathrm{Dy}_{0.1} \mathrm{MnO}_{3}$ prepared by sol-gel technique. Journal of Materials Research and Technology, 8(3), 2996-3003.

[28] Hassan, A. M., Abd El-Wahab, H., Mohy Eldin, A., Naser, A. M., Fouad, O. A., \& Wahba, O. A. G. (2011). Synthesis, Characterization and Application ofMixed Metal OxidesPart $\mathrm{I}=\mathrm{CaMnO}_{3}, \mathrm{Ca}_{2} \mathrm{Cr}_{2} \mathrm{O}_{5}$, $\mathrm{CaSb}_{2} \mathrm{O}_{6}$. Egypt. J. Chem., 54(4), 447-461.

[29] Melo Jorge, M.E., Correia dos Santos, A., \& Nunes, M.R. (2001). Effects of synthesis method on stoichiometry, structure and electrical conductivity of $\mathrm{CaMnO}_{3-\delta}$. International Journal of Inorganic Materials, 3, 915-921.

[30] Mastronardo, E., Qian, X., Coronado, J. M., \& Haile, S. (2019). Fe-doped $\mathrm{CaMnO}_{3}$ for thermochemical heatstorage application. AIP Conference Proceedings, 2126, 210005-1 - 210005-8.

[31] Goldyreva, E. I., Leonidov, I. A., Patrakeev M. V., \& Kozhevnikov, V. L. (2012). Oxygen nonstoichiometry and defect equlibria in $\mathrm{CaMnO}_{3-\delta}$. Journal of Solid State Electrochemistry, 16, 1187-1191. 